\title{
A 10-year retrospective study of melanoma stage at diagnosis in the academic emergency hospital of Sibiu county
}

\author{
MARIA ROTARU ${ }^{1,2}$, CRISTINA RALUCA JITIAN ${ }^{2}$ and GABRIELA MARIANA IANCU ${ }^{1,2}$ \\ ${ }^{1}$ Department of Dermatology, Faculty of Medicine, 'Lucian Blaga' University of Sibiu; \\ ${ }^{2}$ Clinic of Dermatology, Clinical Hospital of Sibiu, 550245 Sibiu, Romania
}

Received October 15, 2018; Accepted January 28, 2019

DOI: $10.3892 / \mathrm{ol} .2019 .10098$

\begin{abstract}
Melanoma is considered to be the most aggressive skin cancer, with an increasing incidence worldwide. An accurate staging of melanoma is crucial in describing the cancer status, estimating prognosis and deciding the optimal treatment solution. In the present study, melanoma staging highlights the importance of early detection, most of the patients having been diagnosed with advanced stages of this skin cancer. A retrospective study was conducted among 117 patients of the Academic Emergency County Hospital of Sibiu, diagnosed with melanoma between 2007 and 2016. The staging of the patients with melanoma was made using the American Joint Committee on Cancer (AJCC) 7th edition, and reconsidered in the light of the AJCC 8th edition. The results showed that the majority of the cases had distant metastases, $40.17 \%$ were diagnosed with stage IV melanoma. $25.65 \%$ of the patients were diagnosed with stage III melanoma, having a regional disease. The rest of the cases had localized melanoma (stages I and II, 30.76\%), while only $3.42 \%$ of them were diagnosed with melanoma in situ, the melanoma type with the greatest chances of survival. Analyzing the Breslow index, it was observed that the most common tumor thickness was 2.1 to $4 \mathrm{~mm}(34.19 \%)$. In conclusion, as the incidence of melanoma increases in Romania, further efforts are needed to improve the early detection of melanoma. There are hopes that with the correct and early diagnosis of melanoma, the mortality rate of this neoplasm will decrease in the future.
\end{abstract}

\section{Introduction}

Melanoma is the most aggressive cutaneous tumor that has shown a constantly increasing incidence in the last decades and a mortality rate that has reached a plateau lately $(1,2)$.

Correspondence to: Dr Gabriela Mariana Iancu, Clinic of Dermatology, Clinical Hospital of Sibiu, 2-4 B-dul Corneliu Coposu, 550245 Sibiu, Romania

E-mail:mgabiancu@yahoo.com

Key words: melanoma, stage, tumor, prognosis, Breslow index
There is an overall sharp discrepancy in melanoma incidence rates reported between Eastern Europe and Western Europe, whereas the mortality rates are similar (3). This is related in part due to the underreporting of this data in Eastern Europe (4).

In Romania, according to the International Agency for Research on Cancer, the melanoma incidence from 5 years ago was of 4.7 cases/100.000 inhabitants, a lower rate in comparison to other European countries (the average rate of 14 cases/100.000 inhabitants), but with a mortality rate (1.7/100.000 inhabitants) comparable with the European countries $(5,6)$. At the same time, melanoma prognosis in Romania and in the neighboring Eastern countries is among the lowest in Europe, with a five-year survival rate of $50-60 \%$, likely reflecting problems of late diagnosis $(7,8)$.

On the one hand, the actinic aggression of the skin, developed after the frequent exposure to the natural or artificial UV radiation, the absence or insufficiency of photoprotection and other factors (9-11) increases the incidence of melanoma. On the other hand, the diagnosis rate of melanoma is higher due to the developments in melanoma diagnosis (dermoscopy (12), immunohistochemistry and cytogenetics), especially in its early stages. In all White Caucasian populations, melanoma represents an important public health issue, involving significant financial and human resources (13). As such, the establishment of an early diagnosis and adoption of the right attitude are tools that can enable to decrease the mortality, morbidity and costs of melanoma and to increase survival in certain tumor stages (14).

The melanoma staging is crucial in appreciating the neoplastic status, assessing the degree of invasion of tumor cells and establishing a certain profile of patients (15).

Using the tumor-node-metastasis (TNM) melanoma staging, the diagnosed patients can be included in different stages, from melanoma in situ (stage 0) until stage IV (metastatic melanoma). This staging method is useful in finding the best treatment options, establishing the prognosis and the survival rate.

The American Joint Committee on Cancer (AJCC) staging of melanoma has highlighted the importance of the Breslow index (BI) in melanoma's medical management (16). Other important parameters in the TNM staging are the presence or absence of ulceration, the tumor's mitotic rate and the tumor microsatellites in lymph nodes (17). 


\section{Materials and methods}

Subjects. We conducted an analytical, observational, retrospective study of melanoma cases diagnosed and dermato-oncologic monitored in Sibiu County, located in the center of Romania. They are diagnosed with melanoma between January 1, 2007 and December 31, 2016 from the Dermatology and Oncology Departments of Sibiu County were included in this study. A total of 117 cases included adult patients (25-87 years), with a sex ratio of 1.17 (female/male). Diagnose of melanoma respected the clinical, dermoscopical, histopathological criteria and in some selected cases the immunohistochemistry melanoma criteria. Excisional biopsy of the tumors were analyzed by the pathologists of our hospital. Processed data included patient characteristics (sex, age and tumor location) and tumor characteristics (clinical forms, Breslow index, the size of the tumor, the presence/absence of the lymph nodes metastases, the degree of distant invasion and the TNM stage). To evaluate the melanoma stages we used the 7th edition of the American Joint Committee on Cancer (AJCC) (16) and it was reconsidered in the light of the AJCC 8th edition (17).

All the patients provide an informed consent to participate in this study which was approved by the Ethics Committee of Clinical Hospital (Sibiu, Romania).

Statistical analysis. The statistical analysis was performed using a free trial of the Statistica software (version 13.3.0; Tibco Software Inc., Palo Alto, CA, USA) with an $\alpha=0.05$ and SPSS Statistics software (version 25.0; IBM Corp., Armonk, NY, USA). The nominal variables were expressed in numbers and percentages. The results are presented as median \pm standard deviation $($ mean $\pm S D)$. To estimate the significant correlations, we calculated the p-values using Shapiro-Wilk and Kolmogorov-Smirnov test. Comparison was evaluated with Chi-square test. $\mathrm{P} \leq 0.05$ was considered to indicate a statistically significant difference.

\section{Results}

A demographic analysis of the studied group revealed a more frequent distribution of melanoma in females $(53.85 \%)$. The patients ages ranged between 25 and 87 years (a median age of $59 \pm 13.17)$. The most affected age category was the one between $51-70$ years of age $(58.12 \%)(\mathrm{P}=0.0420)$ (Table I).

Among women, melanoma was more frequent on the lower extremities (33.33\%). Among men, the most affected anatomical site was the trunk $(53.85 \%)(\mathrm{P}=0.111)$ (Fig. 1).

The distribution of the studied group according to clinical forms of melanoma and BI revealed a high frequency of nodular melanoma (31.62\%) and thick melanomas (48.73\% melanoma diagnosed with a BI of over $2 \mathrm{~mm})(\mathrm{P}<0.001)$ (Table I). The median values of BI were $2.435 \pm 2.38 \mathrm{~mm}$.

TNM staging of all the cases diagnosed with melanoma initially included an analysis based on the T (tumor), $\mathrm{N}$ (lymph nodes) and $\mathrm{M}$ (metastasis) criteria.

Analyzing the $\mathrm{T}$ criterion, the majority of the patients with melanoma were diagnosed with a BI of 2.01-4 mm (T3, 34.19\%). The T3 stage was followed by the T1 and T2 stages (18.81 and 17.95\%), T4 (14.54\%) and Tis (3.42\%). For the melanoma staging where we did not have a BI (11.09\%),

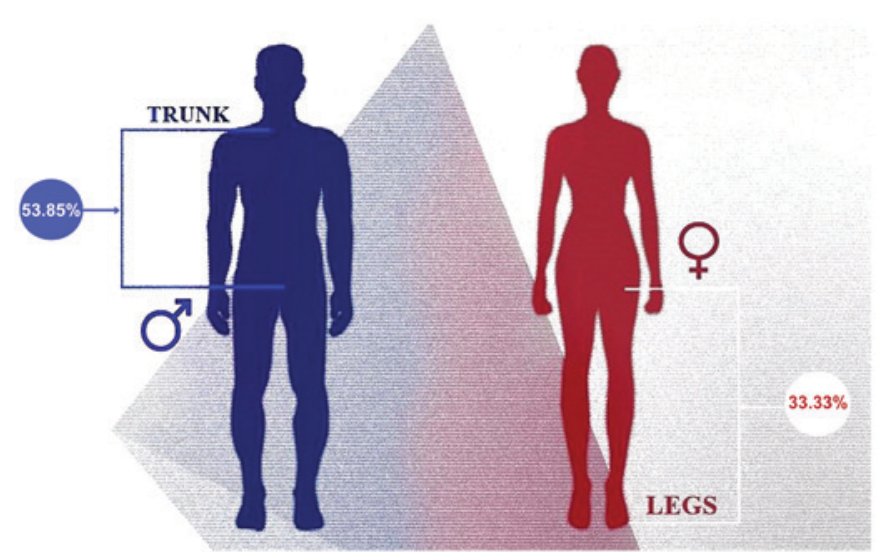

Figure 1. Melanoma distribution according to anatomical areas and sex. Our results are concordant with the literature and revealed that melanoma in women vs. men was most frequent on legs vs. trunk.

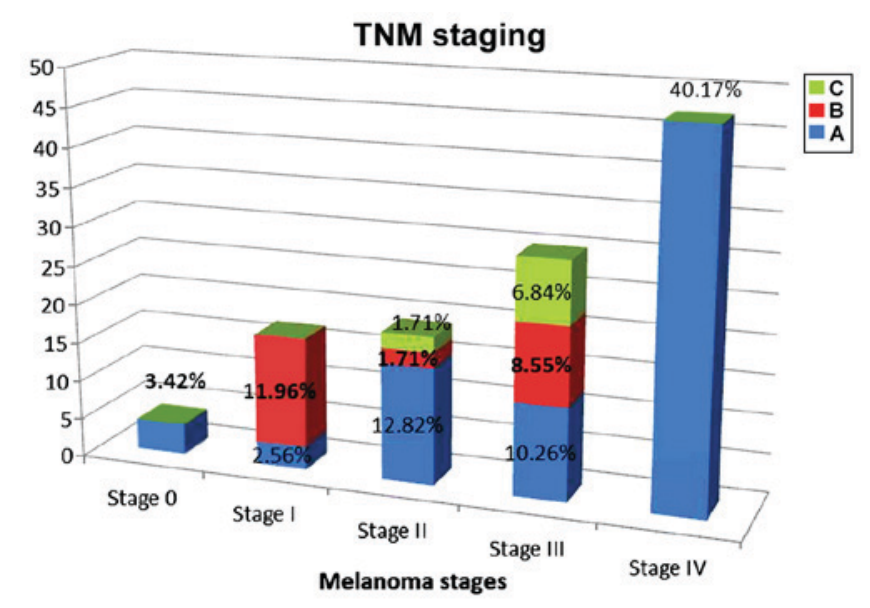

Figure 2. TNM staging in our study. In our study melanoma were diagnosed most common in stage IV and most rare in stage 0 (in situ). In stage I, more cases in stage IB vs. IA were identified. In stages II and III, more patients in stages IIA/IIIA vs. IIB/IIIB/IIIC were identified. TNM, tumor-nodemetastasis.

the tumor we categorized as Tx and the tumor stage was calculated as any $\mathrm{T}$.

Regarding the assessment of the degree of lymph nodes invasion (using the $\mathrm{N}$ criterion) it was observed that the majority of the patients were diagnosed with regional unique or multiple metastases: N2 with 2-3 lymph nodes (48.72\%), N3 with over 4 lymph nodes $(15.38 \%)$, N1 with 1 lymph node $(3.42 \%)$. Approximately $1 / 3$ of the patients were in the N0 stage $(32.48 \%)$.

A percent of $37.61 \%$ of the patients had distant metastases, most frequently at a visceral level (brain, liver, kidney, bone, bone marrow, ovary, uterus, gastric and mesenteric, thyroid). Only $3.42 \%$ of them had pulmonary metastases. Epidermotropic metastases were found in $13.68 \%$ of the patients.

According to the AJCC 8th edition of melanoma TNM staging, the majority of the patients were diagnosed in the stage IVof the disease $(40.17 \%)$. Melanoma cases $(25.65 \%)$ were in stage III, $16.24 \%$ in stage II and $14.52 \%$ in stage I. The low percentage of patients with melanoma in situ $(3.42 \%)$ is worth mentioning (Fig. 2). 
Table I. The distribution of the group according to the age, clinical forms of melanoma and Breslow index.

\begin{tabular}{lcc}
\hline Variables & Cases (n, \%) & P-value \\
\hline Age (years) & $59 \pm 13.17$ & 0.0420 \\
$<30$ & $3(2.57)$ & \\
$31-50$ & $24(20.51)$ & \\
$51-70$ & $68(58.12)$ & \\
$>71$ & $22(18.80)$ & \\
Clinical forms of melanoma & & $<0.001$ \\
Superficial spreading melanoma & $32(27.35)$ & \\
Nodular melanoma & $37(31.62)$ & \\
Lentigo malign melanoma & $2(1.71)$ & \\
Acral melanoma & $1(0.86)$ & \\
Acromic melanoma & $4(3.42)$ & \\
In situ & $4(3.42)$ & \\
Unknown & $37(31.63)$ & \\
Breslow index & & $<0.001$ \\
Under 1 mm & $22(18.81)$ \\
1-2 mm & $21(17.95)$ & \\
Over 2 mm & $57(48.73)$ & \\
In situ & $4(3.42)$ & \\
Unknown & $13(11.09)$ & \\
\end{tabular}

\section{Discussion}

Taking into account that the inhabitants of Sibiu County represent $<5 \%$ of the Romanian population, in the future, the extension of this report at a national level can provide more valuable information on melanoma staging, incidence and mortality rate in Romania.

The increasing incidence of melanoma in the last decades is more evident in male patients, except for the patients under the age of 40 (18). This can be explained by the fact that males do not pay much attention when examining their skin, and find it difficult to apply sunscreen daily. Men also have more hobbies and outdoors activities compered to women.

In this study, the incidence of melanoma was slightly higher in females $(53.85 \%)$, data concordant with the demographic profile of Romanian population (51.19\% women) (19) and similar with to the Rockberg et al study (50.60\%) (6).

Although the average age for the melanoma diagnosis within the studied lot was 59 years, and the most affected age category was 51 to 70 years, it was a notice that $10.25 \%$ of the patients were young persons aged between 25 and 40 years. The study published by Rockberg et al in 3,554 melanoma patients obtained an average diagnosis age of $61.3 \mathrm{vs.} 59$ years in this study. The average lower age and the important number of cases in younger patients, under 40, are warning signs for both the Romanian dermatologists and general population.

The more frequent occurrence of melanoma in women on the lower extremities (33.33\%), and in men on the trunk area $(53.85 \%)$ is a well-known data in the dermatological literature and it is also confirmed by the present study. The distribution according to clinical forms of melanoma reveals the fact that nodular melanoma was more encountered (31.62\%), as opposed to the data from the literature that show a frequency of $50.60 \%$ of the superficial spreading melanoma (20).

The melanoma staging showed that a significant percentage of the patients $(40.17 \%)$ were diagnosed with stage IV of the disease, including distant, multiple organ metastases. Approximately $1 / 4$ of the patients were diagnosed in stage III, being followed by stage II (16.24\%), stage I (14.52\%) and stage 0 (3.42\%). The large number of patients diagnosed in late stages of the disease (stages III and IV, 65.82\%) were correlated with a higher BI (48.73\% had a BI over $2 \mathrm{~mm}$ ). Enninga et al reported $13.3 \%$ late stages of melanoma which were correlated with $\mathrm{BI}>2 \mathrm{~mm}$ (12.3\%) (18). In this study, the data about late melanoma detection in patients with advanced stages corresponds to other publications from Eastern Europe but it is in a sharp contrast with the reported data from Western and Northern Europe (21-25).

Rockberg et al reported results opposed to our data, the majority of the melanoma cases being diagnosed in stages I and II (92\%), while in stage IV being only $1.30 \%$ (6). In stage I there were $14.52 \%$ of the patients in this study vs. $7.80 \%$ of the Andersson et al (26) and $62.50 \%$ of the Eriksson et al (27). Most of the melanoma from the Enninga et al study were diagnosed in incipient stages I and II (83.40\%) and in late stage IV (3.40\%). The correlations between our results and other studies showed that in Eastern Europe as in Romania a much greater effort is needed to improve early detection. The limitation of the study is that the inhabitants of Sibiu County represent a small percentage of Romania's population $(<5 \%)$.

In conclusion, corroborating the results of this study, it may be concluded that melanoma were diagnosed more frequently in nodular forms, with higher BI's, of more than $2 \mathrm{~mm}$, in late stages of disease, with regional and distant metastases.

Considering the clinical impact of these data, better and more efficient measures of tumor prophylaxis are required, with the enhancement of the educational efforts. Furthermore, it is important to raise awareness of the general population of the vital risk induced by the late diagnosis of melanoma. It is imperative to increase skin self-examination by educating individuals how to perform it; also the awareness in general population about the importance of complete dermatological examination for detecting new pigmented lesions or changes in the preexisting lesions should be raised.

\section{Acknowledgements}

Not applicable.

\section{Funding}

No funding was received.

\section{Availability of data and materials}

The datasets used and/or analyzed during the present study are available from the corresponding author on reasonable request.

\section{Authors' contributions}

MR contributed to the conception and design, analysis and interpretation of the data, manuscript drafting and critical 
revision of the manuscript for important intellectual content. CRJ was responsible for the acquisition, analysis and interpretation of the data, manuscript drafting and design. GMI contributed to the analysis and interpretation of the data, manuscript drafting and critical revision of the manuscript for important intellectual content. All authors read and approved the final manuscript.

\section{Ethics approval and consent to participate}

The study was approved by the Ethics Committee of Clinical Hospital (Sibiu, Romania), and a written informed consent was provided by all the patients included in this study.

\section{Patient consent for publication}

Not applicable.

\section{Competing interests}

The authors declare that they have no competing interests.

\section{References}

1. Neagu M, Caruntu C, Constantin C, Boda D, Zurac S, Spandidos DA and Tsatsakis AM: Chemically induced skin carcinogenesis: Updates in experimental models (Review). Oncol Rep 35: 2516-2528, 2016.

2. Karimkhani C, Green AC, Nijsten T, Weinstock MA, Dellavalle RP, Naghavi $\mathrm{M}$ and Fitzmaurice C: The global burden of melanoma: Results from the Global Burden of Disease Study 2015. Br J Dermatol 177: 134-140, 2017.

3. Forsea AM, Del Marmol V, de Vries E, Bailey EE and Geller AC: Melanoma incidence and mortality in Europe: New estimates, persistent disparities. Br J Dermatol 167: 1124-1130, 2012.

4. Barbaric J, Sekerija M, Agius D, Coza D, Dimitrova N, Demetriou A, Safaei Diba C, Eser S, Gavric Z, Primic-Zakelj M, et al: Disparities in melanoma incidence and mortality in South-Eastern Europe: Increasing incidence and divergent mortality patterns. Is progress around the corner? Eur J Cancer 55: 47-55, 2016.

5. European Cancer Information System: Measuring cancer burden and its time trends across. https://ecis.jrc.ec.europa.eu.

6. Rockberg J, Amelio JM, Taylor A, Jörgensen L, Ragnhammar P and Hansson J: Epidemiology of cutaneous melanoma in Sweden-Stage-specific survival and rate of recurrence. Int $\mathbf{J}$ Cancer 139: 2722-2729, 2016.

7. Forsea AM, Del Marmol V, Stratigos A and Geller AC: Melanoma prognosis in Europe: Far from equal. Br J Dermatol 171: 179-182, 2014.

8. Crocetti E, Mallone S, Robsahm TE, Gavin A, Agius D, Ardanaz E, Lopez MC, Innos K, Minicozzi P, Borgognoni L, et al; EUROCARE-5 Working Group: Survival of patients with skin melanoma in Europe increases further: Results of the EUROCARE-5 study. Eur J Cancer 51: 2179-2190, 2015.

9. Zurac S, Neagu M, Constantin C, Cioplea M, Nedelcu R, Bastian A, Popp C, Nichita L, Andrei R, Tebeica T, et al: Variations in the expression of TIMP1, TIMP2 and TIMP3 in cutaneous melanoma with regression and their possible function as prognostic predictors. Oncol Lett 11: 3354-3360, 2016.

10. Caruntu C, Boda D, Constantin C, Caruntu A and Neagu M: Catecholamines increase in vitro proliferation of murine B16F10 melanoma cells. Acta Endo 10: 545-558, 2014.
11. Boda D: Cellomics as integrative omics for cancer. Curr Proteomics 10: 237-245, 2013.

12. Rotaru M, Nati AE, Avrămoiu I, Grosu F and Mălăescu GD: Digital dermoscopic follow-up of 1544 melanocytic nevi. Rom J Morphol Embryol 56: 1467-1472, 2015.

13. Watson M, Geller AC, Tucker MA, Guy GP Jr and Weinstock MA Melanoma burden and recent trends among non-Hispanic whites aged 15-49 years, United States. Prev Med 91: 294-298, 2016.

14. Tripp MK, Watson M, Balk SJ, Swetter SM and Gershenwald JE: State of the science on prevention and screening to reduce melanoma incidence and mortality: The time is now. CA Cancer J Clin 66: 460-480, 2016.

15. McMasters KM, Sondak VK, Lotze MT and Ross MI: Recent advances in melanoma staging and therapy. Ann Surg Oncol 6: 467-475, 1999.

16. Balch CM, Gershenwald JE, Soong SJ, Thompson JF, Atkins MB, Byrd DR, Buzaid AC, Cochran AJ, Coit DG, Ding S, et al: Final version of 2009 AJCC melanoma staging and classification. J Clin Oncol 27: 6199-6206, 2009.

17. Gershenwald JE, Scolyer RA, Hess KR, Sondak VK, Long GV, Ross MI, Lazar AJ, Faries MB, Kirkwood JM, McArthur GA, et al: Melanoma staging: Evidence-based changes in the American Joint Committee on Cancer eighth edition cancer staging manual. CA Cancer J Clin 67: 472-492, 2017

18. Enninga EAL, Moser JC, Weaver AL, Markovic SN, Brewer JD, Leontovich AA, Hieken TJ, Shuster L, Kottschade LA, Olariu A, et al: Survival of cutaneous melanoma based on sex, age, and stage in the United States, 1992-2011. Cancer Med 6: 2203-2212, 2017.

19. Populaţia României pe localităţi (după domiciliu). Institutul Naţional de Statistică România. http://www.insse.ro/cms/sites/ default/files/field/publicatii/populatia_romaniei_dupa domiciliu_ la_1_iul_2016_0.pdf. Accessed July 1, 2016.

20. Youlden DR, Baade PD, Soyer HP, Youl PH, Kimlin MG, Aitken JF, Green AC and Khosrotehrani K: Ten-year survival after multiple invasive melanomas is worse than after a single melanoma: A Population-Based Study. J Invest Dermatol 136: 2270-2276, 2016.

21. Sacchetto L, Zanetti R, Comber H, Bouchardy C, Brewster DH, Broganelli P, Chirlaque MD, Coza D, Galceran J, Gavin A, et al: Trends in incidence of thick, thin and in situ melanoma in Europe. Eur J Cancer 92: 108-118, 2018.

22. Tsoutsos D, Papadopoulos S, Kehagias G, Mara A, Kyriopoulou E, Karonidis A, Spiliopoulos K, Mpalitsaris E, Karapiperis G, Panayotou P, et al: Epidemiological trends in the diagnosis of melanoma in a Southern European population: Analysis of a large database from a tertiary referral center. Melanoma Res 28: 348-358, 2018.

23. Astrua C, Fava P, Brizio M and Savoia P: A study of melanoma in Eastern European migrants in Italy. Eur J Dermatol 27: 139-143, 2017.

24. van der Leest RJ, Zoutendijk J, Nijsten T, Mooi WJ, van der Rhee JI, de Vries E and Hollestein LM: Increasing time trends of thin melanomas in The Netherlands: What are the explanations of recent accelerations? Eur J Cancer 51: 2833-2841, 2015.

25. Helvind NM, Hölmich LR, Smith S, Glud M, Andersen KK, Dalton SO and Drzewiecki KT: Incidence of in situ and invasive melanoma in Denmark from 1985 through 2012: A National Database Study of 24,059 melanoma cases. JAMA Dermatol 151: 1087-1095, 2015.

26. Andersson TM, Eriksson H, Hansson J, Månsson-Brahme E, Dickman PW, Eloranta S, Lambe M and Lambert PC: Estimating the cure proportion of malignant melanoma, an alternative approach to assess long term survival: A population-based study. Cancer Epidemiol 38: 93-99, 2014.

27. Eriksson H, Lyth J, Månsson-Brahme E, Frohm-Nilsson M, Ingvar C, Lindholm C, Naredi P, Stierner U, Carstensen J and Hansson J: Later stage at diagnosis and worse survival in cutaneous malignant melanoma among men living alone: A nationwide population-based study from Sweden. J Clin Oncol 32: 1356-1364, 2014 